\title{
PENGGUNAAN PENDEKATAN CONSTRUCTIVICT GROUNDED THEORY DALAM KAJIAN BULI
}

\section{THE USE OF CONSTRUCTIVIST GROUNDED THEORY APPROACH IN A BULLYING STUDY}

\author{
Nor Junainah Mohd Isa \\ Jabatan Psikologi dan Kaunseling, Fakulti Pembangunan Manusia, \\ Universiti Pendidikan Sultan Idris (UPSI), Malaysia. \\ (Email: junainah@fpm.upsi.edu.my)
}

Received date: $12-06-2019$

Revised date: 17-07-2019

Accepted date: 17-07-2019

Published date: 15-09-2019

To cite this document: Isa, N. J. M. (2019). Penggunaan Pendekatan Constructivist Grounded Theory dalam Kajian Buli. International Journal of Education, Psychology and Counseling, 4 (32), 197-208.

DOI: $10.35631 /$ IJEPC.4320019

\begin{abstract}
Abstrak: Kajian buli di Malaysia kebanyakannya menggunakan pendekatan kuantitatif sebagai reka bentuk kajian. Namun, kaedah ini dilihat tidak mampu memberikan kefahaman mendalam berhubung permasalahan tersebut. Justeru, pendekatan kualitatif dijangka dapat memberikan penjelasan tentang fenomena buli secara lebih menyeluruh. Antara reka bentuk kualitatif yang boleh digunakan adalah constructivist grounded theory (CGT) yang diperkenalkan oleh Charmaz (2006). Bagi memperlihatkan pengaplikasian CGT dalam kajian buli, kertas kerja ini akan menghuraikan pengalaman Pengkaji melaksanakannya secara langkah demi langkah. Diharapkan agar perkongsian ini memberi inspirasi kepada para pengkaji untuk menerapkan pendekatan CGT dalam kajian buli mereka.
\end{abstract}

Kata Kunci: Kualitatif, Constructivist Grounded Theory, Kaedah Kajian, Buli

Abstract: Bullying studies in Malaysia often use quantitative approaches as research designs. However, this method is shown as unable to provide an in-depth understanding of the problem. Hence, qualitative approaches are expected to provide a thorough overview of the bullying phenomenon. One of the approaches that can be used is constructivist grounded theory (CGT) as proposed by Charmaz (2006). To demonstrate the application of CGT in the bullying study, this paper will describe the researcher experience of implementing it step by step. It is hoped that this disclosure will inspire researchers to apply the CGT approach to their own study.

Keywords: Qualitative, Constructivist Grounded Theory, Methodology, Bullying 


\section{Pendahuluan}

Kajian buli dalam kalangan murid di negara ini dipelopori oleh Profesor Dr. Noran Fauziah Yaakub di mana beliau giat membentangkan dapatan di dalam pelbagai seminar dan persidangan sejak tahun 2001 (Suraiya, 2001; Rohana, 2003; Marzita, 2004). Apabila kes buli menjadi serius sehingga menyebabkan kematian seorang murid pada tahun 2004, pengkajipengkaji di seluruh Malaysia merasa terpanggil untuk meneliti fenomena ini agar dapat memahami dan menangani permasalahan yang sedang berlaku. Walau bagaimanapun, majoriti kajian yang dijalankan berbentuk kuantitatif. Hanya segelintir pengkaji menggunakan pendekatan kualitatif dengan menjalankan kajian kes.

Kecenderungan pengkaji memilih pendekatan kuantitatif sepanjang lapan tahun pertama isu buli diketengahkan boleh dikaitkan dengan matlamat kajian mereka, iaitu mengumpul data preliminari tentang fenomena buli dalam kalangan murid sekolah rendah dan menengah di seluruh Malaysia. Malah, kajian-kajian tinjauan ini mendapat tajaan geran penyelidikan daripada pihak kerajaan. Antara pengkaji yang terlibat termasuklah Noran Fauziah, Anne Althea, Mizuar, Azmi, dan Rosna (2002), Noran Fauziah, Rajendran, dan Ahmad Jazimin (2003), Kamarulzaman, Abu Bakar, Abdul Malek, Omar, Abd. Latif et al. (2006), Kamarulzaman, Abu Bakar, Abdul Malek, Abd. Latif, Abd. Kadir et al. (2007), dan Azizi, Yusufboon, Shahrin, Mohammad Sharif, dan Zurhana (2008).

Selain mendapatkan profil tentang pembuli, mangsa, lokasi buli, tujuan serta kesan buli, pengkaji-pengkaji mula menguji keberkesanan rawatan yang mereka cadangkan, iaitu dengan menjalankan kajian eksperimen bagi mengukur kesan intervensi. Sebagai contoh, Abdul Malek (2004, 2007) memperkenalkan kaunseling kelompok berstruktur, khususnya untuk murid yang melakukan perbuatan buli, manakala Jamalsafri, Rabiatul-Adawiyah, Abdul Jalil, dan Syed Mohamad (2012) pula mencadangkan pelaksanaan program intervensi 2Bs: I'm a Buddy not a Bully terhadap murid-murid di sekolah menengah.

Sehingga tahun 2018, majoriti kajian buli berbentuk kuantitatif dan tertumpu pada murid sekolah, khususnya yang berumur antara 13 tahun hingga 17 tahun. Kemungkinan terdapat kajian-kajian berbentuk kualitatif, atau melibatkan peserta daripada kelompok berbeza, namun tidak dapat dicapai secara atas talian menyebabkan kesukaran untuk mengakses maklumat tersebut. Selain itu, jenis buli yang menjadi fokus kajian pula adalah berbentuk tradisional, iaitu buli fizikal, buli bahasa, buli perhubungan, buli isyarat, dan peras ugut. Penyelidikan berhubung buli siber hanya dimulakan oleh Sarina (2015) yang menjalankan kajian berbentuk kuantitatif, manakala Hanif Suhairi (2015) pula membuat penelitian kualitatif.

Oleh sebab kajian kuantitatif tidak berupaya memberi pemahaman yang jitu tentang masalah buli dari sudut pandang individu yang semestinya unik berbanding orang lain, maka keperluan menjalankan kajian yang dapat memberikan gambaran terperinci tentang permasalahan ini perlu dititikberatkan oleh pengkaji-pengkaji di Malaysia. Menurut Othman (2017), penjelasan tentang fenomena sosial boleh dilakukan dengan menggunakan reka bentuk seperti etnografi, kajian kes, fenomenologi, dan grounded theory (GT). Keempat-empat kaedah ini memerlukan pengkaji untuk turun ke lapangan dan bertemu sendiri dengan para peserta bagi mendapatkan maklumat. Walau bagaimanapun, fokus dan tujuan setiap reka bentuk ini berbeza antara satu sama lain. 
Jika diteliti perkembangan kajian buli di luar negara, kebanyakan pengkaji mula memilih constructivist grounded theory (CGT) sebagai reka bentuk kajian. Pengkaji-pengkaji seperti Mishna, Saini, dan Solomon (2009), Thornberg, Halldin, Bolmsjö, dan Petersson (2013), serta Mazzone, Thornberg, Stefanelli, Cadei, dan Caravita (2018) bersetuju bahawa kaedah GT mampu memberikan jawapan kepada persoalan-persoalan yang lebih mendalam terhadap isu berkaitan buli. Malah, sumbangan utama kajian, iaitu pembinaan teori substantif sudah tentu memberikan manfaat kepada semua pihak yang terlibat dalam intervensi buli. Oleh itu, wajar sekiranya kajian buli di negara ini turut menggunakan pendekatan yang sama agar pemahaman yang jelas terhadap pengalaman dan makna masyarakat tempatan tentang permasalahan buli dapat diterokai.

\section{Pendekatan Constructivist Grounded Theory (CGT)}

Pendekatan CGT merupakan satu aliran GT yang utama di dunia selain Classic GT dan Straussian GT. Gelombang aliran ketiga dalam dunia penyelidikan GT ini diasaskan oleh Kathy Charmaz melalui penerbitan buku Constructing Grounded Theory yang diterbitkan pada tahun 2006. Beliau merupakan anak didik kedua-dua pelopor GT iaitu Glaser dan Strauss yang memperkenalkan reka bentuk kajian ini pada tahun 1967. Walau pun terdapat pertentangan antara aliran beliau dengan guru-gurunya, namun variasi GT diterima baik dalam dunia penyelidikan kualitatif.

Umumnya, CGT mengekalkan konsep-konsep asas dalam GT seperti memungut data dan menganalisisnya secara serentak, membina kod dan kategori berdasarkan data yang diperoleh, menulis memo, dan melaksanakan pensampelan teoretikal (Charmaz, 1996, 2015). Perbezaan antara aliran ini dengan aliran lain pula termasuklah falsafah yang dipegang, penggunaan literatur, peranan pengkaji, prosedur pengekodan, dan kriteria penilaian kajian. Berbanding dua aliran utama GT, CGT boleh dianggap lebih fleksibel (Charmaz, 1990, 2006, 2014) kerana memberi kebebasan kepada pengkaji untuk memberi makna terhadap makna yang disampaikan oleh peserta. Sungguh pun begitu, CGT amat menekankan aspek kualiti kajian. Perkara ini diakui sendiri oleh Corbin dan Strauss (2008) di mana mereka mendapati kriteria yang dicadangkan oleh Charmaz adalah paling komprehensif berbanding garis panduan lain dalam literatur.

\section{Aplikasi Pendekatan CGT}

Berikut merupakan perkongsian Pengkaji mengenai pelaksanaan kajian buli menggunakan pendekatan constructivist grounded theory (CGT):

\section{Matlamat dan Soalan Kajian}

Kajian CGT memberi perhatian terhadap tindakan dan proses sosial (Sbaraini, Carter, Evans, \& Blinkhorn, 2011) masyarakat, iaitu dengan bermatlamatkan untuk mencari jawapan terhadap persoalan "apa", "bagaimana" (Charmaz, 2008) dan "mengapa" (Charmaz, 2012, 2016) seseorang itu bertingkah laku atau bertindak tertentu dalam mana-mana situasi. Justeru, kajian CGT tidak didasari dengan hipotesis awal (Gehrels, 2013), sebaliknya dimulai dengan soalan terbuka (Charmaz, 2006, 2014) terhadap pengalaman yang ingin diteroka (Charmaz, 1990).

Dalam kajian ini, Pengkaji berminat untuk memahami perspektif ibu bapa terhadap permasalahan buli anak-anak. Soalan awal yang Pengkaji kemukakan adalah 1) Bagaimanakah ibu bapa mendefinisikan sesuatu perbuatan itu sebagai perlakuan buli?, dan 2) Bagaimanakah cara ibu bapa menangani permasalahan buli anak mereka? Berdasarkan soalan-soalan berbentuk umum ini, Pengkaji dapat meneroka pengalaman, pengetahuan, nilai dan sikap, serta 
strategi menangani buli yang telah dan akan ibu bapa lakukan, khususnya terhadap insiden buli dalam kalangan anak di peringkat sekolah rendah.

\section{Pemilihan Peserta}

Morse (2007) mengemukakan empat syarat pensampelan dalam kajian GT, iaitu pensampelan mudah, pensampelan bertujuan, pensampelan teoretikal, dan temu bual kumpulan teoretikal. Bagi mematuhi saranan ini, Pengkaji telah mengenal pasti seorang bapa yang mempunyai anak di peringkat sekolah rendah. Kemudian, Pengkaji melanjutkan pemilihan peserta dengan kaedah pensampelan bola salji supaya mudah untuk mendapatkan "... individu atau latar yang difikirkan mewakili pengalaman terhadap fenomena yang menjadi fokus kajian" (Othman, 2006:67). Apabila kategori tentatif ditemui semasa menganalisis data temu bual ke-10, Pengkaji mula menjalankan pensampelan teoretikal supaya ciri-ciri dalam setiap kategori dapat dipenuhi. Pengkaji mendapati kategori teoretikal menjadi padat semasa menganalisis data temu bual yang ke-21. Namun, proses temu bual dan pengekodan diteruskan sehingga sesi ke-29 agar ketepuan teoretikal benar-benar diperoleh.

Setelah teori dan model berjaya dibina, Pengkaji mengadakan temu bual berkumpulan dengan kelompok ibu bapa yang terdiri daripada lima orang guru bimbingan dan kaunseling. Temu bual berkumpulan sebegini merupakan satu teknik triangulasi dalam kajian GT seperti yang dinyatakan oleh Jonsen dan Jehn (2009). Matlamat daripada perjumpaan ini bukanlah untuk mengesahkan teori substantif atau model berkenaan, sebaliknya bertujuan untuk mendapatkan maklum balas peserta berhubung kategori-kategori dan model teoretikal tersebut. Sekiranya terdapat maklumat tambahan yang dicadangkan, maka Pengkaji perlu kembali ke lapangan untuk mendapatkan data yang berkaitan. Jika tiada, penulisan laporan akhir boleh mula dilakukan.

\section{Pengumpulan Data}

Pengkaji mengumpul data menggunakan temu bual intensif separa berstruktur dan secara bersemuka. Memandangkan permasalahan buli anak-anak merupakan satu isu yang sensitif, maka Pengkaji menggunakan vignet situasi hipotetikal buli sebagai alat untuk mengumpul maklumat daripada ibu bapa. Penggunaan vignet ini memberi ruang keselesaan dan rasa selamat kepada para peserta untuk berkongsi pengalaman, pandangan, perasaan dan jangkaan terhadap persoalan-persoalan yang Pengkaji ajukan.

Dalam kajian ini, Pengkaji menggunakan lima vignet yang mewakili lima jenis perlakuan buli, iaitu buli fizikal, buli perhubungan, buli isyarat, buli bahasa, dan peras ugut. Pengkaji membentuk kelima-lima vignet ini berdasarkan kes sebenar yang diperoleh daripada kajian Noran Fauziah (2006), Noran Fauziah, Fatimah, Zuria, Salimah, dan Louis (2006), Salimah, Noran Fauziah, Zuria, dan Louis (2006) serta Noran Fauziah, Fatimah, dan Ahmad Jazimin (2009). Pembinaan vignet juga mematuhi prosedur pembinaan alat ujian agar kejelasan, ketepatan dan kerelevanannya dapat diperoleh.

Semasa menjalankan temu bual, Pengkaji mengemukakan vignet terlebih dahulu sebelum membuat penerokaan mendalam menggunakan soalan-soalan terbuka. Rajah 1 merupakan contoh vignet dan beberapa soalan lanjutan yang telah Pengkaji gunakan dalam kajian. 
Vignet \#2: Boo Lan murid lelaki yang berkulit cerah, berbadan gempal dan mempunyai bentuk muka yang bulat. Walaupun Boo Lan periang, namun dia mudah menangis apabila diejek oleh rakan-rakannya. Barubaru ini, dua batang gigi hadapannya telah patah. Setiap kali dia bercakap, rakan-rakan akan mentertawakannya sambil berteriak, "Rongak, Rongak, Boo Lan, Bulat". Boo Lan menangis kerana malu tetapi rakan-rakannya akan bersorak dengan gembira.

\section{A. Soalan Permulaan}

Berdasarkan situasi:

1. Adakah anda menganggap tingkah laku murid itu sebagai buli? Apa yang menyebabkan anda menyatakan sedemikian?

2. Pada pandangan anda, apakah yang dimaksudkan dengan buli?

\section{B. Soalan Pertengahan}

1. Adakah anak anda pernah mengalami peristiwa seperti dalam Vignet \#2? Ceritakan apa yang berlaku.

2. Apakah yang akan anda lakukan sekiranya mengetahui anak membuli/dibuli/menyaksikan buli?

\section{Soalan Akhir}

1. Pada pandangan anda, apakah yang sepatutnya dilakukan oleh ibu bapa jika anak mereka membuli/dibuli/menyaksikan buli?

2. Sebagai ibu bapa, apakah yang dapat anda lakukan supaya anak anda tidak menjadi pembuli/mangsa? Apakah langkah awal yang boleh anda buat untuk mencegahnya?

\section{Rajah 1: Vignet Situasi Hipotetikal Buli dan Soalan Lanjutan}

Sepanjang temu bual berlangsung, Pengkaji membuat rakaman secara audio dengan mendapatkan persetujuan bertulis daripada setiap peserta terlebih dahulu. Keperluan untuk melakukan rakaman audio sangat dititikberatkan dalam kajian CGT kerana Charmaz (2006, 2014, 2015) berpendapat kaedah ini berupaya membantu pengkaji-pengkaji semasa membuat transkripsi. Selain mengelakkan maklumat tertinggal, rakaman juga membolehkan setiap pengkaji memberi fokus terhadap temu bual yang dijalankan.

\section{Pengekodan}

Charmaz $(2006,2014)$ memperkenalkan kaedah pengekodan awal dan pengekodan terfokus untuk menganalisis data kajian CGT. Kaedah ini ternyata berbeza dengan apa yang diperkenalkan oleh tokoh-tokoh utama GT seperti Glaser dan Strauss (1967), Glaser (2007), serta Strauss dan Corbin (1998). Glaser (2007, 2016) yang mempelopori Classic GT mencadangkan dua tahap pengekodan. Tahap pertama disebut sebagai pengekodan substantif yang terdiri daripada dua jenis teknik, iaitu pengekodan terbuka dan pengekodan terpilih, manakala tahap kedua pula melibatkan proses pengekodan teoretikal. Bagi Strauss dan Corbin (1998) yang sinonim dengan Straussian GT, mereka memperkenalkan tiga tahap pengekodan, iaitu pengekodan terbuka, pengekodan berpaksi, dan pengekodan terpilih. Perbezaan kaedah 
pengekodan bagi ketiga-tiga aliran utama GT ini mencerminkan pegangan falsafah bagi tokohtokoh tersebut.

Oleh sebab Pengkaji menggunakan pendekatan CGT, maka dua jenis pengekodan digunakan dalam kajian. Semasa membuat pengekodan awal, Pengkaji membaca transkrip secara perkataan demi perkataan, dan baris demi baris sambil melontarkan soalan-soalan kepada diri sendiri seperti “Apa yang berlaku di sini?”, dan “Apa yang peserta ingin sampaikan?”. Langkah ini bertujuan untuk memecahkan data kepada komponen-komponen yang lebih kecil bagi membentuk kod-kod awal. Dengan berbantukan perisian Atlas-ti, Pengkaji memperincikan, menggabungkan, membuang, serta menyusun kod-kod awal sehingga menghasilkan 132 kod dan sembilan kategori tentatif. Contoh kod awal dan kategori tentatif adalah seperti di dalam Jadual 1 di bawah:

Jadual 1: Kod Awal dan Kategori Tentatif

\begin{tabular}{|c|c|}
\hline Kod Awal & Kategori Tentatif \\
\hline $\begin{array}{l}\text { 1. Melakukan buli: bergurau/bermain-main } \\
\text { 2. Melakukan buli: dipengaruhi rakan } \\
\text { 3. Melakukan buli: melepaskan tekanan }\end{array}$ & a. Punca buli \\
\hline $\begin{array}{l}\text { 4. Menjadi mangsa: ada kelebihan } \\
\text { 5. Menjadi mangsa: kurang kemahiran sosial } \\
\text { 6. Menjadi mangsa: mudah tersentuh perasaan }\end{array}$ & b. Individu yang terlibat \\
\hline
\end{tabular}

Setelah kod-kod awal dibentuk, Pengkaji meneroka semula kod-kod ini untuk mengenal pasti kod terfokus. Kod terfokus merupakan kod utama yang boleh dilihat berdasarkan kekerapannya di dalam data. Proses pengekodan terfokus ini juga melibatkan penelitian terhadap hubungan antara setiap kod supaya sub kategori, dan kategori utama boleh dibina. Kedua-dua kategori ini menggantikan kategori tentatif yang telah dicadangkan semasa pengekodan awal. Jadual 2 di bawah merupakan contoh kod utama, sub kategori, dan kategori yang terhasil daripada proses pengekodan terfokus:

Jadual 2: Kod Utama, Sub Kategori, dan Kategori dalam Fasa Pengekodan Terfokus

\begin{tabular}{lll}
\hline Kod Utama & Sub Kategori & Kategori Utama \\
\hline $\begin{array}{l}\text { 1. Melakukan buli: bergurau } \\
\text { 2. Melakukan buli: dipengaruhi rakan }\end{array}$ & i. Tujuan buli & a. Pencetus buli \\
3. Melakukan buli: melepaskan tekanan & & \\
& & \\
$\begin{array}{l}\text { 4. Menjadi mangsa: ada kelebihan } \\
\text { 5. Menjadi mangsa: kurang kemahiran }\end{array}$ & ii. Ciri-ciri mangsa & a. Pencetus buli \\
$\quad$ sosial & & \\
$\begin{array}{l}\text { 6. Menjadi mangsa: mudah tersentuh } \\
\text { perasaan }\end{array}$ &
\end{tabular}


Apabila kategori utama telah berjaya ditemui, Pengkaji mengenal pasti tema-tema dengan melihat hubungan antara setiap kategori tersebut. Penelitian terhadap hubungan antara tema pula membolehkan Pengkaji mengemukakan teori substantif dan mencadangkan model teoretikal. Jadual 3 di bawah memaparkan contoh sub kategori, kategori, dan tema yang terhasil:

\section{Jadual 3: Sub Kategori, Kategori dan Tema}

\begin{tabular}{|c|c|c|}
\hline Sub Kategori & Kategori & Tema \\
\hline $\begin{array}{l}\text { 1. Jenis buli } \\
\text { 2. Tujuan membuli }\end{array}$ & i. Definisi buli & a. Pengetahuan buli \\
\hline $\begin{array}{l}\text { 3. Ciri-ciri mangsa } \\
\text { 4. Ciri-ciri pembuli }\end{array}$ & ii. Pencetus buli & a. Pengetahuan buli \\
\hline
\end{tabular}

\section{Pembinaan Teori}

Pengkaji membina teori substantif setelah memperhalus hubung kait antara setiap tema, kategori, sub kategori, dan kod yang ditunjukkan daripada keseluruhan data. Umumnya, teori yang terbatas kepada latar buli ini merupakan hasil konstruksi Pengkaji terhadap makna yang diberikan oleh kesemua peserta kajian. Dalam erti kata lain, teori yang diperoleh secara induktif ini merupakan interpretasi Pengkaji terhadap apa yang disampaikan oleh mereka. Seperti yang ditegaskan oleh Charmaz (2014:17), “...neither data nor theories are discovered... We construct our grounded theories through our past and present involvements and interactions with people, perspectives, and research practices".

Bagi mengilustrasikan teori, Pengkaji mengemukakan model teoretikal yang menunjukkan perkaitan antara setiap tema seperti dalam Rajah 2 berikut:

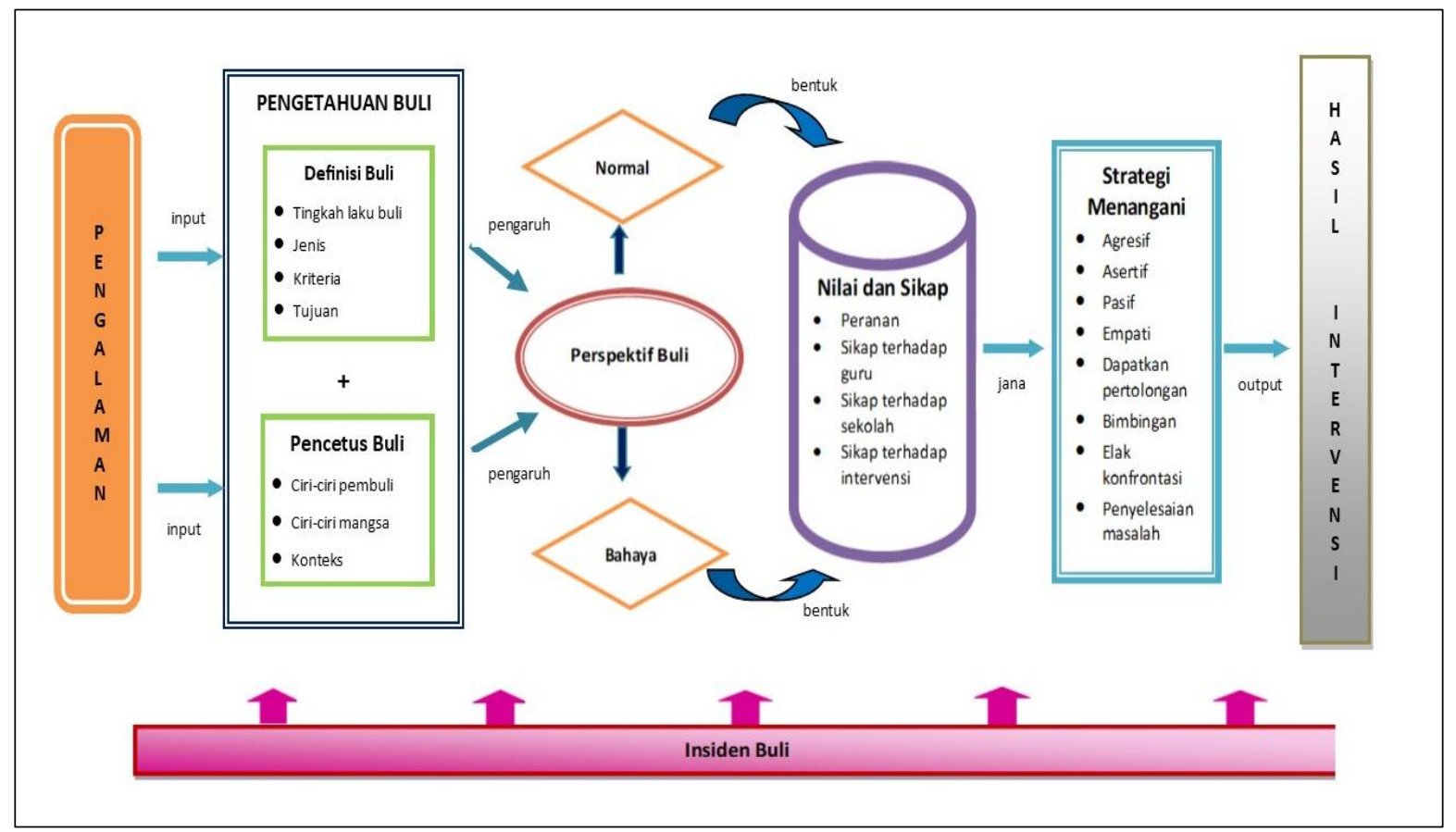

Rajah 2: Model Perspektif Ibu Bapa Mengenai Permasalahan Buli Anak-anak 


\section{Perbandingan Konstan}

Kaedah perbandingan konstan melibatkan proses menganalisis data secara berterusan. Melalui perbandingan antara data dengan data, data dengan kod, kod dengan kod, kod dengan kategori, kategori dengan kategori (Charmaz, 2006, 2014), serta teori dengan literatur (Mills, Bonner, \& Francis, 2006), pembinaan teori dapat dibuat dengan lebih teratur dan sistematik (Glaser \& Strauss, 1967). Selain itu, ketekalan kajian juga dapat ditingkatkan (Corbin \& Strauss, 1990) kerana kesemua data diteliti berulang kali. Dalam kajian ini, Pengkaji telah menjalankan proses perbandingan konstan sebaik sahaja data pertama diperoleh sehinggalah teori substantif berjaya ditemui.

\section{Penulisan Memo}

Memo merupakan nota-nota ringkas yang terdiri daripada persoalan, pandangan, jangkaan atau apa sahaja yang terlintas dalam fikiran Pengkaji semasa berhadapan dengan data. Dalam kajian grounded theory, penulisan memo dibuat selepas temu bual dilaksanakan (Sbaraini, Carter, Evans, \& Blinkhorn, 2011; Ridzwan \& Mohd Nor Azhari, 2016), serta ketika proses menganalisis data dilakukan (Glaser, 2007; Charmaz, 2015). Melalui catatan ringkas ini, setiap pengkaji dapat mengekalkan fokus (Charmaz, 2000), meneroka idea tentang kategori-kategori yang dibentuk (Charmaz, 2014), dan membina teori (Glaser, 2007; Holton, 2008) dengan lebih sistematik.

Dalam kajian yang Pengkaji lakukan, memo bukan sahaja bertindak sebagai kerangka dan pemandu arah, malah menjadi auditor bagi setiap aktiviti dan proses penyelidikan. Terdapat empat jenis memo yang telah Pengkaji tulis, iaitu memo aktiviti, memo temu bual, memo kes, dan memo konseptual. Bagi memo aktiviti, Pengkaji merekodkan keseluruhan aktiviti kajian seperti perancangan harian berhubung pemungutan dan pengekodan data, senarai temu janji, serta tarikh pertemuan dengan pakar-pakar. Memo temu bual pula merujuk kepada refleksi kendiri Pengkaji terhadap proses temu bual yang telah dijalankan, manakala memo kes menggambarkan pandangan Pengkaji terhadap pengalaman peserta berdasarkan verbatim temu bual yang telah disediakan. Memo terakhir, iaitu memo konseptual dicatat semasa mengekod data sebagaimana disarankan oleh Charmaz (2006, 2014, 2015), Glaser (2007) dan Holton (2008). Memo ini mencerminkan proses konstruksi dan konseptualisasi Pengkaji ketika berurusan dengan keseluruhan data.

\section{Tinjauan Literatur}

Dalam menjalankan kajian berbentuk CGT, sorotan dan penulisan literatur tidak digalakkan untuk dibuat sebelum proses pengumpulan dan penganalisisan data dilakukan (Kenny \& Fourie, 2015; Ramalho et al., 2015). Sebagaimana yang ditegaskan oleh Charmaz (1996, 2006, 2012), penelitian terhadap kajian-kajian terdahulu seharusnya ditangguhkan sehinggalah analisis konseptual terhadap data telah dibentuk. Katanya, “...you can let this material lie fallow until after you have developed your categories and the analytic relationships between them. Then begin locating your work within the relevant literatures" (2006: 166). Justeru, Pengkaji telah menyediakan satu bab khas di akhir kajian untuk membandingkan dapatan dengan literatur semasa. Melalui kaedah perbandingan konstan, Pengkaji dapat mengenal pasti keberadaan dapatan kajian dengan teori-teori formal sedia ada.

\section{Penulisan Laporan}

Langkah terakhir dalam kajian CGT adalah menulis laporan. Pada peringkat awal, Pengkaji menyusun dan meneliti kesemua memo agar dapat menjana idea bagi mengarang draf awal penulisan. Melalui perbandingan dengan literatur, Pengkaji mengembangkan idea dan membuat 
penambahbaikan terhadap penulisan laporan. Setelah berkali-kali membuat semakan dan pemurnian, Pengkaji mengemukakan laporan akhir untuk dijilidkan.

Secara keseluruhannya, proses pelaksanaan kajian buli menggunakan pendekatan CGT dapat dilihat daripada Rajah 3 di bawah:

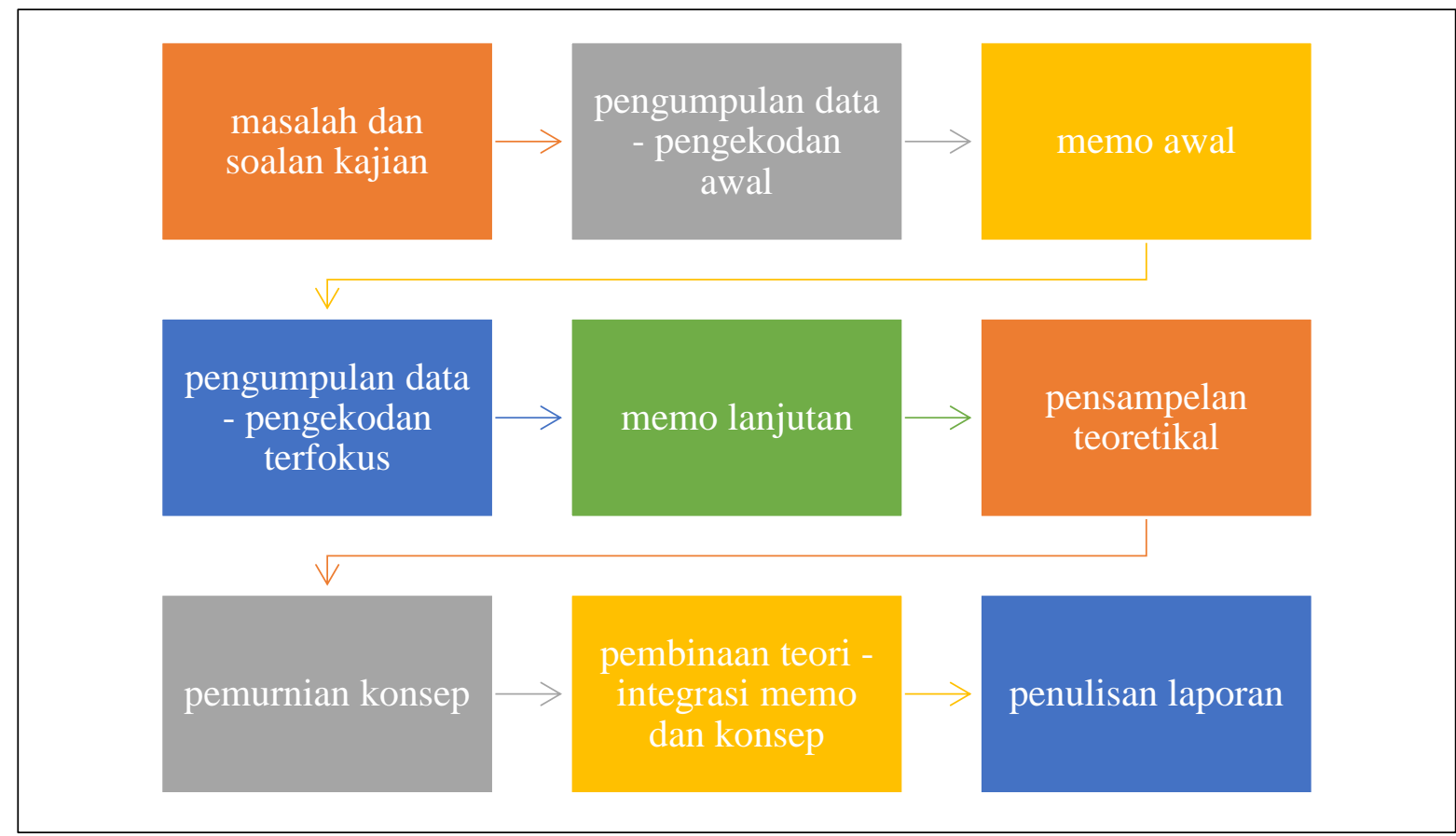

Rajah 3: Proses CGT dalam Kajian Buli

\section{Rumusan}

Constructivist grounded theory menawarkan peluang kepada pengkaji-pengkaji dalam bidang buli untuk meneroka dan memahami perkara-perkara tersembunyi yang tidak mampu dijelaskan oleh kajian berskala besar. Berdasarkan pengalaman menjalankan kajian buli menggunakan pendekatan CGT, Pengkaji berpendapat reka bentuk penyelidikan kualitatif ini mampu memberikan hasil yang bermanfaat dalam bidang intervensi buli di negara ini. Pengkaji berharap lebih ramai ilmuwan yang menerapkan pendekatan ini dalam kajian mereka agar penghasilan teori-teori substantif yang mewakili suara rakyat Malaysia dapat diketengahkan dan dikongsi ke peringkat global.

\section{Rujukan}

Abdul Malek Abdul Rahman. (2004). Kesan kaunseling kelompok latihan kemahiran sosial terhadap tingkah laku langsang buli di kalangan pelajar-pelajar sekolah menengah. Tesis $\mathrm{PhD}$ yang tidak diterbitkan. Universiti Kebangsaan Malaysia.

Abdul Malek Abdul Rahman. (2007). The effectiveness of cognitive behaviour group counselling on bullies amongst the secondary schools students in Malaysia. Jurnal Bitara, (1) 21-32.

Azizi Yahaya, Yusufboon, Shahrin Hashim, Mohammad Sharif Mustafa, \& Zurhana Muhamad. (2008). Indeks perlakuan buli di kalangan pelajar-pelajar sekolah menengah dan rendah di Malaysia. Laporan Penyelidikan. Universiti Teknologi Malaysia.

Charmaz, K. (1990). 'Discovering' chronic illness: Using grounded theory. Social Science \& Medicine, 30 (11), 1161-1172. http://dx.doi.org/10.1016/0277-9536(90)90256-r 
Charmaz, K. (1996). The search for meanings - Grounded theory. Dalam Smith, J.A., Harré, R., \& Van Langenhove, L. (Eds). Rethinking methods in psychology. London: Sage. 2749.

Charmaz, K. (1996). The search for meanings - Grounded theory. Dalam Smith, J.A., Harré, R., \& Van Langenhove, L. (Eds). Rethinking methods in psychology. London: Sage. 2749.

Charmaz, K. (2000). Grounded theory: Objectivist and contructivist methods. Dalam Denzin, N.K., \& Lincoln, Y. (Eds). The handbook of qualitative research. Thousand Oaks, CA: Sage Publications, Inc. 509-535.

Charmaz, K. (2006). Constructing grounded theory: A practical guide through qualitative analysis. London: Sage.

Charmaz, K. (2008). Grounded theory as an emergent method. Dalam Hesse-Biber, S.N., \& Leavy, P. (Eds). Handbook of emergent methods. New York: The Guilford Press. 155172 .

Charmaz, K. (2012). The power and potential of grounded theory. A Journal of the BSA MedSoc Group, 6(3), 2-15. http://www.medicalsociologyonline.org/resources/Vol6Iss3/MSo600x_The-Power-and-Potential-Grounded-Theory_Charmaz.pdf

Charmaz, K. (2014). Constructing grounded theory. (2 ${ }^{\text {nd. }}$ Ed.). Thousand Oaks, CA: Sage.

Charmaz, K. (2015b). Teaching theory construction with initial grounded theory tools: A reflection on lessons and learning. Qualitative Health Research, 25(12), 1610-1622. https://doi.org/10.1177/1049732315613982

Charmaz, K. (2016). Constructivist grounded theory. The Journal of Positive Psychology 12(3), 299-300. Dikongsi oleh pengarang melalui ResearchGate pada 6 Oktober 2017.

Corbin, J., \& Strauss, A. (1990). Grounded theory research: Procedures, canons, and evaluative criteria. Qualitative Sociology, 13(1), 3-21. http://med-fom-familymedresearch.sites.olt.ubc.ca/files/2012/03/W10-Corbin-and-Strauss-grounded-theory.pdf

Corbin, J., \& Strauss, A. (2008). Basics of qualitative research. ( $3^{\text {rd. }}$ Ed.). Thousand Oaks, CA: Sage

Gehrels, S. (2013). Grounded theory application in doctorate research. Research in Hospitality Management, 3 (1). http://dx.doi.org/10.2989/RHM.2013.3.1.3.1216

Glaser, B.G. (2007). Remodeling grounded theory. Historical Social Research, Supplement, 19, 47-68. http://nbnresolving.de/urn:nbn:de:0168-ssoar-288341

Glaser, B.G. (2016). Open coding descriptions. The Grounded Theory Review, 15(2), 108-110. http://groundedtheoryreview.com/2016/12/19/open-coding-descriptions/

Glaser, B.G., \& Strauss, A. (1967). The discovery of grounded theory: Strategies for qualitative research. New Brunswick: Aldine Transaction.

Hanif Suhairi Abu Bakar. (2015) The emergence themes of cyberbullying among adolescences. International Journal of Adolescence and Youth, 20 (4), 393-406. https://doi.org/10.1080/02673843.2014.992027

Holton, J.A. (2008). Grounded theory as a general research methodology. The Grounded Theory Review, 7(2). http://groundedtheoryreview.com/2008/06/30/grounded-theoryas-a-general-research-methodology/

Jamalsafri Saibon, Rabiatul-Adawiyah Ahmad Rashid, Abdul Jalil Ali, \& Syed Mohamad Syed Abdullah. (2012). Enhancing school children's knowledge and awareness on bullying through the 2Bs program. International Proceedings of Economics Development and Research, 47 (15), 68-70.

Jonsen, K., \& Jehn, K.A. (2009). Using triangulation to validate themes in qualitative studies. Qualitative Research in Organizations and Management: An International Journal, 4 (2), 123-150. http://dx.doi.org/10.1108/17465640910978391 
Kamarulzaman Kamaruddin, Abu Bakar Nordin, Abdul Malek Abdul Rahman, Abd. Latif Gapor, Abd. Kadir Arifin, Amir Hasan Dawi, Normah Othman, Mohmadisa Hashim, \& Ismail Abdul Raoh. (2007). Kajian ke atas Buli di Malaysia 2. Laporan Penyelidikan. Universiti Pendidikan Sultan Idris.

Kamarulzaman Kamaruddin, Abu Bakar Nordin, Abdul Malek Abdul Rahman, Omar Abdull Kareem, Abd. Latif Gapor, Abd. Kadir Arifin, Amir Hasan Dawi, Normah Othman, Khuan Wai Bing, Muhammad Nadzir Ibrahim, Mohmadisa Hashim, Ismail Abdul Raoh, \& Abdul Halim Ali. (2006). Kajian ke atas buli di Malaysia Fasa 1. Laporan Penyelidikan. Universiti Pendidikan Sultan Idris.

Kenny, M., \& Fourie, R. (2015). Contrasting Classic, Straussian, and Constructivist grounded theory: Methodological and philosophical conflicts. The Qualitative Report, 20(8), 1270-1289. http://www.nova.edu/ssss/QR/QR20/8/kenny1.pdf

Marzita Abdullah. (2004, 17 Februari). Kena buli: Mangsa tidak tahu mengapa. Utusan Malaysia.

Mazzone, A., Thornberg, R., Stefanelli, S., Cadei, L., \& Caravita, S.C.S. (2018). "Judging by the cover": A grounded theory study of bullying towards same-country and immigrant peers. Children and Youth Services Review, 91, 403-412. Dikongsi oleh pengarang melalui ResearchGate pada 16 Julai 2018.

Mishna, F., Saini, M., \& Solomon, S. (2009). Ongoing and online: Children and youth's perceptions of cyber bullying. Children and Youth Services Review, 31, 12221228.https://tspace.library.utoronto.ca/bitstream/1807/71778/1/Mishna\%2C\%20Ongoi ng\%20and\%20Online.pdf

Morse, J.M. (2007). Sampling in grounded theory. Dalam Bryant, A., \& Charmaz, K. (Eds). The SAGE handbook of grounded theory: Paperback edition. London: Sage. 229-244.

Noran Fauziah Yaakub, Anne Althea Christopher, Mizuar Nasruddin, Azmi Abu Samah, \& Rosna Awang Hashim. (2002). Bullying among Malaysian school children: Some preliminary findings. Dlm. Noraini M. Noor, Zafar A. Ansari, \& Ashiq A. Shah (pnyt.). Psychology of well-being and self-actualization. hlm. 90-106. International Islamic University Malaysia.

Noran Fauziah Yaakub, Fatimah Haron, \& Ahmad Jazimin Jusoh. (2009). Pencegahan buli di sekolah. Kuala Lumpur: Utusan Publications \& Distributors Sdn. Bhd

Noran Fauziah Yaakub, Fatimah Haron, Zuria Mahmud, Salimah Mohd. Ali, \& Louis, G.J. (2006). Hentikan buli di sekolah anda: Panduan sekolah menengah. Kuala Lumpur: Sutrapadu (M) Sdn. Bhd.

Noran Fauziah Yaakub, Rajendran Nagappan, \& Ahmad Jazimin Jusoh. (2003). Bullying among National and National Type (Tamil and Chinese) primary school children with reference to Perak - Some preliminary findings. Proceeding on Investing in Innovation, 235-240.

Noran Fauziah Yaakub. (2006). Buli di sekolah: Apa yang kita tahu dan apa yang boleh kita buat. Kuala Lumpur: Sutrapadu (M) Sdn. Bhd.

Othman Lebar. (2006). Penyelidikan kualitatif: Pengenalan kepada teori dan metod. Tanjong Malim: Universiti Pendidikan Sultan Idris.

Othman Lebar. (2017). Penyelidikan kualitatif: Pengenalan kepada teori dan metode. (Edisi Kedua). Tanjong Malim: Universiti Pendidikan Sultan Idris.

Ramalho, R., Adams, P., Huggard, P., \& Hoare, K. (2015). Literature review and constructivist grounded theory methodology. Forum: Qualitative Social Research, 16(3), Art. 19. http://nbn-resolving.de/urn:nbn:de:0114-fqs1503199

Ridzwan Che Rus, \& Mohd Nor Azhari Azman. (2016). Pengaruh minat terhadap pembentukan pekerja berkemahiran di Malaysia: Kajian kes pelatih Institut Latihan Perindustrian 
Kuala Lumpur (ILPKL). Geografia: Malaysian Journal of Society and Space, 12 (3), 168

http://www.ukm.my/geografia/v2/index.php?cont=a\&item=2\&thn=2016\&vol=12\&iss ue $=3 \&$ ver $=$ loc

Rohana Man. (2003, 30 September). Membuli - Kenali jenis, mangsa dan pemangsa. Utusan Malaysia.

Salimah Mohd. Ali, Noran Fauziah Yaakub, Zuria Mahmud, \& Louis, G.J. (2006). Hentikan buli di sekolah anda: Panduan sekolah rendah. Kuala Lumpur: Sutrapadu (M) Sdn. Bhd.

Sarina Yusup. (2015). Parental attachment and cyberbullying among Malaysian children. Tesis Sarjana yang tidak diterbitkan. Universiti Putra Malaysia.

Sbaraini, A., Carter, S.M., Evans, R.W., \& Blinkhorn, A. (2011). How to do a grounded theory study: A worked example of a study of dental practices. BMC Medical Research Methodology, 11 (128). http://www.biomedcentral.com/1471-2288/11/128

Strauss, A., \& Corbin, J. (1998). Basics of qualitative research: Techniques and procedures for developing grounded theory. ( $2^{\text {nd. }}$ Ed.). Thousand Oaks, CA: Sage.

Suraiya Mohd Nor. (2001, 7 September). Buli gugat semangat belajar. Berita Harian.

Thornberg, R., Halldin, K., Bolmsjö, N., \& Petersson, A. (2013). Victimising of school bullying: A grounded theory. Research Papers in Education, (28)3, 309-329. Dikongsi oleh pengarang melalui ResearchGate pada 9 Jun 2017. 